\title{
Células solares bifaciais industriais em lâminas de silício finas: análise de passivação de superfícies e tipo de silício
}

\author{
(Bifacial solar cells on thin silicon wafers: \\ analysis of the surface passivation and type of silicon)
}

\author{
V. C. Osório ${ }^{1}$, A. Moehlecke ${ }^{1 *}$, I. Zanesco ${ }^{1}$

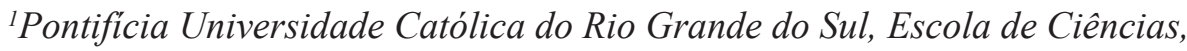 \\ Programa de Pós-Graduação em Engenharia e Tecnologia de Materiais, \\ Núcleo de Tecnologia em Energia Solar, \\ Av. Ipiranga 6681, 90619-900, Porto Alegre, RS, Brasil
}

\begin{abstract}
Resumo
O objetivo deste trabalho foi analisar a passivação de superfícies com $\mathrm{SiO}_{2}$ em células solares bifaciais fabricadas em lâminas finas bem como avaliar a influência do tipo de silício monocristalino utilizado para fabricar as células solares. A estrutura implementada foi $\mathrm{a}^{+} \mathrm{pp}^{+}$, com fósforo na face frontal e boro e alumínio na face posterior, formando uma região seletiva de campo retrodifusor. Foram usadas lâminas de silício Cz (Czochralski) e FZ (float zone) com $145 \mu$ m de espessura e implementou-se uma etapa térmica para crescer uma camada de $\mathrm{SiO}_{2}$ para passivar as superfícies. O óxido passivou as superfícies, proporcionando um aumento de $0,5 \%$ absolutos na eficiência das células solares fabricadas em silício FZ. As células solares produzidas em Si-Cz não obtiveram o mesmo aumento porque apresentaram uma elevada resistência em série. A célula solar fina mais eficiente foi fabricada com silício FZ e com superfícies passivadas, atingindo eficiência de $14,5 \%$ e de $11,1 \%$, para iluminação pela face $\mathrm{n}^{+}$e $\mathrm{p}^{+}$, respectivamente. As células em $\mathrm{Si}-\mathrm{Cz}$, mesmo com menor tempo de vida inicial dos portadores de carga minoritários, atingiram eficiências um pouco menores que estes valores.
\end{abstract}

Palavras-chave: células solares, células solares bifaciais, lâminas finas de silício, passivação de superfícies.

\begin{abstract}
The aim of this paper was to analyze the surface passivation based on $\mathrm{SiO}_{2}$ for thin bifacial solar cells as well as to evaluate the influence of the type of substrate used to fabricate the cells. The $n^{+} p p^{+}$structure was implemented, with phosphorus in the front face and boron and aluminum in the rear face, forming in the latter a selective back surface field. The Czochralski (Cz) and float zone (FZ) monocrystalline silicon wafers (145 $\mu \mathrm{m}$ thick) were used and a thermal step to grow a SiO layer to passivate the surfaces was implemented. The oxide passivated the surfaces, providing an absolute increase of $0.5 \%$ in FZ silicon solar cell efficiency. The solar cells produced in $\mathrm{Si}-\mathrm{Cz}$ did not present the same increase because they showed a high series resistance. The more efficient thin solar cell was manufactured with Si-FZ and with oxidized surfaces, reaching the efficiency of $14.5 \%$ and $11.1 \%$, for illumination by the $n^{+}$and $p^{+}$faces, respectively. The Si-Cz solar cells, even with a lower initial lifetime of minority carriers, reached slightly lower efficiencies than Si-FZ solar cells.
\end{abstract}

Keywords: solar cells, bifacial solar cells, thin silicon wafers, surface passivation.

\section{INTRODUÇÃO}

A estrutura padrão atual das células solares industriais de silício é a $\mathrm{n}^{+} \mathrm{pp}^{+}$, com a face frontal $\mathrm{n}^{+}$dopada com fósforo e posterior $\mathrm{p}^{+}$com alumínio. $\mathrm{O}$ fósforo é difundido em toda a superfície da lâmina e o alumínio, depositado por serigrafia sobre a face posterior, é difundido em forno de esteira. Esta camada de $\mathrm{Al}$ compensa a dopagem tipo $\mathrm{n}$, formando uma região $\mathrm{p}^{+}$que repele portadores de carga minoritários. Esta região na face posterior é denominada de região de campo retrodifusor ou BSF, back surface field. As células solares com espessuras da ordem de 180 a $200 \mu \mathrm{m}$ atingem

*moehleck@pucrs.br eficiências de $15 \%$ a $17 \%$ usando silício monocristalino [1]. Uma forma de reduzir os custos de fabricação das células solares é por meio do uso de lâminas de menor espessura, pois a lâmina corresponde a $58 \%$ do custo [1]. Porém, se for usada a tecnologia padrão baseada na deposição de alumínio na face posterior, pode ocorrer o abaulamento da lâmina durante o processo de difusão e queima da pasta metálica, conduzindo à quebra das lâminas na sequência do processamento. $\mathrm{O}$ abaulamento ocorre devido aos diferentes coeficientes de expansão térmica da liga $\mathrm{Al}-\mathrm{Si}$ e do $\mathrm{Si}$, produzindo uma contração do contato posterior [2].

Regiões $\mathrm{p}^{+}$formadas pela difusão localizada de alumínio, em forma de malha, ou por boro difundidoem toda a superfície posterior podem ser alternativas para evitar o problema do 
abaulamento. Além disto, como o alumínio não é depositado em toda a face posterior, permite-se que o dispositivo possa ser usado como célula solar bifacial. Este tipo de célula solar é ativo em ambas as faces e, quando aplicado em módulos concentradores de radiação ou em estruturas que permitam aproveitar a radiação de albedo, pode proporcionar ganhos de potência [3-6]. Segundo estudos recentes [7], a potência excedente proporcionada pela radiação incidente na face posterior pode viabilizar as estruturas bifaciais para a redução dos custos da eletricidade produzidas por módulos fotovoltaicos. Em lâminas de silício monocristalino tipo $\mathrm{p}$, dopadas com boro, as células solares bifaciais mais eficientes foram desenvolvidas por pesquisadores da Hitachi utilizando uma estrutura do tipo triodo, tendo um contato elétrico na face frontal tipo $\mathrm{n}^{+} \mathrm{e}$ dois na face posterior, sobre regiões $\mathrm{n}^{+}$e $\mathrm{p}^{+}$[8]. Foram usadas lâminas de silício crescido pela técnica da fusão zonal flutuante (FZ, float zone), com espessura da ordem de $250 \mu \mathrm{m}$ e as eficiências de $21,3 \%$ e 19,8\% foram obtidas para iluminação pela face frontal e posterior, respectivamente. Com estruturas simplificadas $\mathrm{n}^{+} \mathrm{pp}^{+}$, isto é, com uma junção na face frontal e uma região de BSF na face posterior, Yang et al. [9] e Janßen et al. [10] apresentaram células solares de alta eficiência usando lâminas de silício $\mathrm{Cz}$ (Czochralski) com espessura da ordem de $200 \mu \mathrm{m}$. Os primeiros publicaram resultados de células solares de área igual a $149 \mathrm{~cm}^{2}$ e com malhas metálicas obtidas por serigrafia, atingindo eficiências de 16,6\% (iluminação pela face frontal) e de $12,8 \%$ (face posterior) [9]. Janßen et al. [10] também usaram contatos metálicos depositados por serigrafia, mas em vez de usar uma região $\mathrm{p}^{+}$ uniforme em toda a face posterior, uma malha metálica de Al foi depositada para produzir uma região de BSF localizada. A eficiência para iluminação pela face frontal foi de $17 \%$ e pela face posterior foi de $10,3 \%$.

Usando lâminas de silício monocristalino crescido pela técnica $\mathrm{Cz}$, de $120 \mu \mathrm{m}$ de espessura, Recart [11] desenvolveu dispositivos $\mathrm{n}^{+} \mathrm{pp}^{+}$bifaciais de $24,7 \mathrm{~cm}^{2}$. O emissor $\mathrm{n}^{+}$foi obtido pela difusão de fósforo usando como fonte de dopante o $\mathrm{POCl}_{3}$ e a região $\mathrm{p}^{+}$, na face posterior, foi obtida pela deposição de pastas ricas em boro e difusão em forno de esteira. As células solares $\mathrm{n}^{+} \mathrm{pp}^{+}$com regiões $\mathrm{n}^{+}$e $\mathrm{p}^{+}$homogêneas atingiram as eficiências de $14,3 \%$ e $10,8 \%$, com iluminação frontal (região $\mathrm{n}^{+}$) e posterior $\left(\mathrm{p}^{+}\right)$, respectivamente [11]. Células solares bifaciais finas de 4 $\mathrm{cm}^{2}$, com $130 \mu \mathrm{m}$ de espessura, alcançaram eficiências de $16,9 \%$ e $10,4 \%$ para iluminação pela face $\mathrm{n}^{+} \mathrm{e} \mathrm{p}^{+}$. Estas células fotovoltaicas foram fabricadas com lâminas de silício crescido pela técnica $\mathrm{FZ}$, com contatos metálicos obtidos por evaporação em alto vácuo, processo inviável na indústria de células solares [12]. Com estrutura $n^{+} p$, superfície frontal e posterior passivada com $\mathrm{SiN}_{\mathrm{x}}$ e região de BSF de Al localizada somente no contato elétrico da face posterior, foram obtidas as eficiências de 14,6\%/13,6\% (frontal/posterior) em dispositivos de área reduzida $\left(4 \mathrm{~cm}^{2}\right)$ e com lâminas de silício $\mathrm{Cz}$ de $140 \mu \mathrm{m}$ de espessura [13]. Regiões de BSF seletivo também foram propostas para células solares bifaciais fabricadas em lâminas finas [14,
15]. No BSF seletivo, o boro é difundido em toda a face posterior e o $\mathrm{Al}$ somente no contato metálico em forma de malha, conforme esquematizado na Fig. 1. Usando lâminas de $\mathrm{Si}-\mathrm{Cz}$ tipo $\mathrm{p}$ de $150 \mu \mathrm{m}$ de espessura, foram fabricados dispositivos bifaciais de $61,58 \mathrm{~cm}^{2}$ com eficiências de $14,0 \%$ e de $10,4 \%$ para iluminação pela face $\mathrm{n}^{+} \mathrm{e}^{+}$, respectivamente [15]. Nestas células solares, a região $\mathrm{n}^{+}$foi obtida mediante difusão de fósforo usando $\mathrm{POCl}_{3}$ como fonte. A região $\mathrm{p}^{+}$foi produzida pela deposição de boro por spin-on e difusão em forno de tubo de quartzo bem como pela deposição de pasta de alumínio por serigrafia e difusão em forno de esteira. As superfícies não foram recobertas com filmes passivadores. Os mesmos autores [14] também demonstraram que as regiões localizadas de $\mathrm{Al}$ na face posterior somente podem ser usadas se um filme passivador de superfícies e, ao mesmo tempo, barreira para difusão de contaminantes for depositado sobre as lâminas antes do processo de metalização. Lâminas finas de silício tipo $\mathrm{n}$, dopadas com fósforo, também podem ser usadas na fabricação de células bifaciais, obtendo-se a estrutura $\mathrm{n}^{+} \mathrm{np}^{+}$ou $\mathrm{p}^{+} \mathrm{nn}^{+}$. Por exemplo, Jimeno et al. [16] fabricaram dispositivos $\mathrm{n}^{+} \mathrm{np}^{+}$com metalização por serigrafia que atingiram eficiência de $13,2 \%$ na face $\mathrm{n}^{+} \mathrm{n}$ e $12,7 \%$ na face $\mathrm{p}^{+} \mathrm{n}$, usando silício $\mathrm{Cz}$ com $160 \mu \mathrm{m}$ de espessura [16]. As células bifaciais foram processadas com regiões $\mathrm{n}^{+} \mathrm{e} \mathrm{p}^{+}$ homogêneas obtidas a partir da deposição de pastas com dopantes e difusão em forno de esteira, processos de alta produtividade.

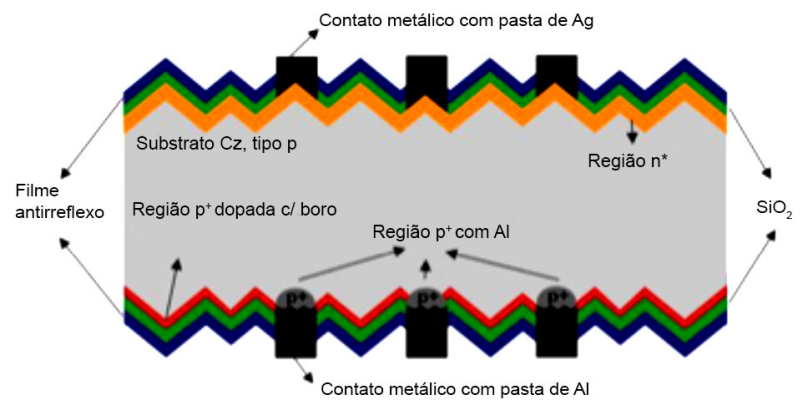

Figura 1: Esquema de célula solar bifacial fina com região $\mathrm{p}^{+}$ seletiva.

[Figure 1: Schematic of thin bifacial solar cell with selective $p^{+}$ region.]

O objetivo deste trabalho foi analisar a influência do tipo de silício ( $\mathrm{Cz}$ e FZ) nas características elétricas de células solares bifaciais finas bem como a passivação de superfícies com camada de $\mathrm{SiO}_{2}$ crescido termicamente. As células solares com espessura de $145 \mu \mathrm{m}$ foram desenvolvidas com a estrutura $\mathrm{n}^{+} \mathrm{pp}^{+}$, com região $\mathrm{p}^{+}$seletiva obtida pela difusão de boro a partir de dopante depositado por spin-on e pela difusão de alumínio depositado por serigrafia, sendo a área de alumínio definida por uma máscara em forma de malha.

\section{MATERIAIS E MÉTODOS}

Foram utilizadas lâminas de silício monocristalino $\mathrm{Cz}$ (Czochralski) e FZ (float zone), tipo p, dopadas com 
boro e orientação dos planos cristalográficos de $\{100\}$. As lâminas de silício $\mathrm{Cz}$ tinham resistividade de $2 \Omega$.cm, espessura inicial de 535-585 $\mu \mathrm{m}$ e o tempo de vida dos portadores de carga minoritários $(\tau)$ nas lâminas, medido pela técnica do decaimento da fotocondutividade e com as lâminas imersas em HF $49 \%$, foi da ordem de $42 \pm 5 \mu$ s. As lâminas de silício FZ apresentaram resistividade de 1-5 $\Omega . \mathrm{cm}$, espessura inicial de $280 \mu \mathrm{m}$ e o $\tau$ foi de $165 \pm 12$ $\mu$ s, evidenciado a melhor qualidade do silício FZ frente ao crescido pela técnica $\mathrm{Cz}$. A espessura das lâminas foi reduzida para aproximadamente $145 \mu \mathrm{m}$ mediante um ataque químico constituído de $210 \mathrm{~g}$ de $\mathrm{KOH}$ e $1,6 \mathrm{~L}$ de água deionizada $\left(\mathrm{H}_{2} \mathrm{O}_{\mathrm{DI}}\right)$, mantido a $90{ }^{\circ} \mathrm{C}$ [17]. Para as lâminas $\mathrm{Cz}$, o tempo de ataque foi de 110 min e para as $\mathrm{FZ}$ foi de 35 min porque as espessuras iniciais eram diferentes. Esta solução foi empregada porque não havia no mercado a disponibilidade de lâminas finas.

O processo de fabricação utilizado neste trabalho está resumido na Fig. 2. Depois da redução da espessura, realizouse o ataque anisotrópico das superfícies em um banho de $\mathrm{KOH}$, isopropanol e $\mathrm{H}_{2} \mathrm{O}_{\mathrm{DI}}$ para formar micropirâmides na superfície da lâmina. Em seguida, realizou-se uma limpeza RCA das lâminas baseada em soluções químicas como $\mathrm{H}_{2} \mathrm{O}_{2}, \mathrm{NH}_{4} \mathrm{OH}, \mathrm{HCl}$ e $\mathrm{H}_{2} \mathrm{O}_{\mathrm{Dr}}$. O líquido contendo boro, PBF20, da Filmtronics, foi depositado por spin-on sobre uma face das lâminas e estas foram introduzidas em uma estufa para evaporação dos solventes. Após a deposição do dopante, foi realizada a difusão de boro em forno com tubo de quartzo na temperatura de $1000{ }^{\circ} \mathrm{C}$ por $20 \mathrm{~min}$, seguida de processo de oxidação. A camada de silicato de boro e óxido de silício formada teve a função de proteger a face dopada com boro do processo seguinte de difusão de fósforo [18]. Após a difusão de boro, foi depositada resina fotossensível por spin-on na superfície com silicato de boro e a mesma foi secada em estufa. O óxido na face sem resina foi atacado em solução de HF tampão e foi realizada a limpeza da resina com acetona, álcool isopropílico e $\mathrm{H}_{2} \mathrm{O}_{\mathrm{DI}}$. Para retirar todos os resíduos, as lâminas foram submetidas novamente à limpeza RCA. A difusão de fósforo foi realizada em um forno de alta temperatura com tubo de quartzo usando $\mathrm{POCl}_{3}$ como fonte. $\mathrm{O}$ fósforo foi difundido a $875^{\circ} \mathrm{C}$, com pré-deposição de 60 min e redistribuição de 10 min. A resistência de folha (R॰) da região $\mathrm{n}^{+}$foi de $43 \pm 2$ $\Omega / \square$, com concentração de superfície $\left(C_{\mathrm{S}}\right)$ de $4,3.10^{20} \mathrm{~cm}^{-3}$ e espessura de $0,4 \mu \mathrm{m}$ [15]. A região $\mathrm{p}^{+}$, também depois do processo térmico de difusão de fósforo, apresentou as seguintes características: $\mathrm{R} \square=30 \pm 2 \Omega / \square, \mathrm{C}_{\mathrm{S}}=2.10^{19} \mathrm{~cm}^{-3}$ e espessura de $1 \mu \mathrm{m}$ [15]. Na sequência, extraíram-se os silicatos de fósforo e de boro mediante um ataque químico em ácido fluorídrico e realizou-se a limpeza RCA.

Foram separadas lâminas de controle que não foram oxidadas e que passaram diretamente para a etapa de deposição de filme antirreflexo. Em um grupo de lâminas, uma camada de $\mathrm{SiO}_{2}$ com espessura da ordem de $10 \mathrm{~nm}$ foi crescida a $800^{\circ} \mathrm{C}$ para reduzir a recombinação nas superfícies. Sobre a face $\mathrm{n}^{+}$, depositou-se um filme antirreflexo (AR) de $\mathrm{TiO}_{2}$ por evaporação em alto vácuo com canhão de elétrons.

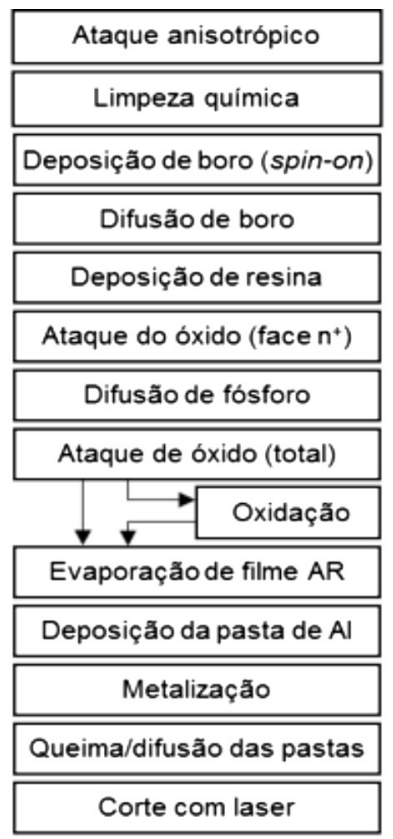

Figura 2: Processo de fabricação desenvolvido para produção de células solares bifaciais.

[Figure 2: Fabrication process developed to produce bifacial solar cells.]

Embora as células bifaciais devam receber filme AR em ambas as faces, optou-se por não depositar este filme antes da metalização posterior para não prejudicar a formação da região de BSF seletiva com a pasta de Al. Neste caso, o filme deve ser depositado depois da metalização.

A metalização posterior foi realizada por serigrafia com a pasta de alumínio PV381, da DuPont, que teve a função de formar o contato e a região de BSF. A malha metálica frontal foi implementada por serigrafia utilizando a pasta de prata PV159, da DuPont. As pastas foram secadas em forno de esteira a $200{ }^{\circ} \mathrm{C}$ e queimadas no mesmo forno, a $840{ }^{\circ} \mathrm{C}$ para lâminas sem camada de $\mathrm{SiO}_{2}$ e $850{ }^{\circ} \mathrm{C}$ para lâminas com $\mathrm{SiO}_{2}$ [14]. No processo de queima, a pasta de prata perfura as camadas de $\mathrm{SiO}_{2}$ e $\mathrm{TiO}_{2}$, contatando eletricamente a região $\mathrm{n}^{+}$e a pasta de alumínio perfura a camada de $\mathrm{SiO}_{2}$, formando a região de BSF e o contato posterior. As faces frontal e posterior receberam uma malha de metal com trilhas de $100 \mu \mathrm{m}$ de largura, duas barras coletoras de $2 \mathrm{~mm}$ de largura e com um fator de sombra de 9,5\%. Para finalizar, as bordas das células solares foram cortadas por meio de um sistema com radiação laser para obter células solares pseudoquadradas de $80 \times 80 \mathrm{~mm}$, com área de $61,58 \mathrm{~cm}^{2}$.

As células solares foram caracterizadas eletricamente mediante a medida da curva corrente-tensão elétrica (I-V) nas condições padrão: $1000 \mathrm{~W} / \mathrm{m}^{2}$, espectro solar AM1,5 $\mathrm{G}$ e $25^{\circ} \mathrm{C}$. As medidas foram realizadas com iluminação pela face $\mathrm{n}^{+}$e $\mathrm{p}^{+}$. A partir da curva I-V, determinaram-se os seguintes parâmetros: a) $\mathrm{V}_{\mathrm{OC}}$, tensão de circuito aberto; b) $\mathrm{J}_{\mathrm{SC}}$, densidade de corrente de curto-circuito; c) FF, fator de forma; e d) $\eta$, eficiência. Nas células solares mais eficientes foi depositado o filme AR sobre a face $\mathrm{p}^{+}$, depois do processo de metalização e da primeira caracterização 
elétrica. As células solares de maior eficiência foram analisadas pela técnica LBIC (light beam induced current) [19], com o equipamento WT 2000 PV da Semilab, em quatros comprimentos de onda: 648, 845, 953 e $973 \mathrm{~nm}$. Com a medida da corrente de curto-circuito nestes quatro comprimentos de onda foi possível estimar o comprimento de difusão $\left(\mathrm{L}_{\mathrm{D}}\right)$ dos portadores de carga minoritários.

\section{RESULTADOS E DISCUSSÃO}

A Tabela I apresenta os parâmetros elétricos médios das células solares fabricadas. Em relação ao tipo de lâmina utilizado, observou-se que a melhor qualidade da lâmina FZ (float zone), comprovada pelo maior tempo de vida dos portadores de carga minoritários, resultou em células solares com maiores valores médios de parâmetros elétricos. Os dispositivos em lâminas $\mathrm{FZ}$ com $\mathrm{SiO}_{2}$, em relação às de silício $\mathrm{Cz}$ (Czochralski), apresentaram $\mathrm{V}_{\mathrm{OC}}$, $\mathrm{J}_{\mathrm{SC}}$ e $\eta$ maiores em $12 \mathrm{mV}, 2,2 \mathrm{~mA} / \mathrm{cm}^{2}$ e 2,5\% (absolutos), respectivamente. Nas células solares sem passivação (sem $\mathrm{SiO}_{2}$ ), a diferença entre os parâmetros elétricos dos dispositivos com $\mathrm{Si}-\mathrm{FZ} \mathrm{e} \mathrm{Cz}$ foi menor. Neste caso, ao usar Si-FZ, os parâmetros $\mathrm{V}_{\mathrm{OC}}, \mathrm{J}_{\mathrm{SC}}$ e $\eta$ foram incrementados em $+10 \mathrm{mV}, \quad+0,6 \mathrm{~mA} / \mathrm{cm}^{2}$ e $+0,6 \%$ (absolutos), respectivamente. Com iluminação pela região de BSF seletivo, a diferença em eficiência entre células solares FZ e Cz foi de $0,9 \%$ e $2 \%$ absolutos para células sem e com $\mathrm{SiO}_{2}$, respectivamente. A maior diferença observada nos dispositivos com $\mathrm{SiO}_{2}$ era esperada, pois como houve passivação de superfícies, a influência do $\tau$ tornou-se mais evidente nas características elétricas. O FF (fator de forma) foi relativamente baixo em todas as células solares, evidenciando a existência de resistência em série elevada. Para as lâminas $\mathrm{FZ}$, observou-se que o $\mathrm{SiO}_{2}$ proporcionou um aumento na eficiência para ambos os modos de iluminação. Por outro lado, nas células com lâminas $\mathrm{Cz}$, a oxidação final não acarretou em melhoria dos dispositivos devido ao menor FF. No entanto, as lâminas foram oxidadas no mesmo processo térmico e não houve razão para as $\mathrm{Cz}$ terem maior espessura de $\mathrm{SiO}_{2}$, o que dificultaria o contato elétrico. Uma hipótese para esta redução no FF é a geração de defeitos localizados no processo térmico de oxidação, tais como a precipitação de oxigênio, pois em lâminas de silício $\mathrm{Cz}$ a concentração de oxigênio pode ser de até duas ordens de magnitude acima da encontrada em lâminas FZ. No entanto, este comportamento pode ser diferente se forem usadas lâminas de $\mathrm{Si}-\mathrm{Cz}$ de outros fabricantes.

A Tabela II resume os resultados das células solares fabricadas que apresentaram a maior eficiência e os valores obtidos por simulação com o programa computacional PC-1D [20]. Foram fixados os seguintes parâmetros nas simulações: espessura de $145 \mu \mathrm{m}$, refletância da superfície texturada frontal com filme $\mathrm{AR}$ de $\mathrm{TiO}_{2}$, fator de sombra de 9,5\% e resistividade de base de $2 \Omega . c m$ para lâminas $\mathrm{Cz}$ e FZ. Para ajustar os resultados obtidos das simulações com os experimentais, variou-se $o \tau$, a velocidade de recombinação na superfície $\mathrm{n}^{+}\left(\mathrm{S}_{\mathrm{f}}\right)$, a velocidade de recombinação na superfície posterior com BSF $\left(\mathrm{S}_{\mathrm{p}}\right)$ e a resistência em série específica $\left(\mathrm{r}_{\mathrm{S}}{ }^{*}\right)$. Para ambos os tipos de substrato, a camada de $\mathrm{SiO}_{2}$ reduziu a $\mathrm{S}_{\mathrm{f}}$ e $\mathrm{S}_{\mathrm{p}}$ em duas ordens de magnitude, de $10^{7}$ para $10^{5} \mathrm{~cm} / \mathrm{s}$. Para superfícies $\mathrm{n}^{+}$, o valor foi acima do previsto em [21], de $4,3.10^{4} \mathrm{~cm} / \mathrm{s}$ para $\mathrm{C}_{\mathrm{S}}=4,3.10^{20} \mathrm{~cm}^{-3}$. Em regiões $\mathrm{p}^{+}$com $\mathrm{C}_{\mathrm{S}}=1,6.10^{19} \mathrm{~cm}^{-3}$, o valor de $\mathrm{S}_{\mathrm{p}}$ esperado seria, para superfícies texturadas, de $5,2.10^{4} \mathrm{~cm} / \mathrm{s}$ (o valor correspondente a uma superfície polida, $4,7.10^{3} \mathrm{~cm} / \mathrm{s}$, multiplicado por um fator de 11 para ajustar a recombinação relativa a superfícies texturadas) [22]. Assim, embora a camada de $\mathrm{SiO}_{2}$ tenha passivado as superfícies, sua qualidade não foi elevada. A redução na velocidade de recombinação em superfície para os

Tabela I - Parâmetros elétricos médios de células solares fabricadas com lâminas de silício $\mathrm{Cz}$ e FZ, com e sem camada de $\mathrm{SiO}_{2}$. O filme AR foi depositado somente sobre a face $\mathrm{n}^{+}$. [Table I - Average electrical parameters of solar cell fabricated by using $C z$ and FZ silicon, with and without $\mathrm{SiO}_{2}$ layer. The ARC was deposited only on the $n^{+}$face.]

\begin{tabular}{cccccc}
\hline Substrato & $\mathrm{SiO}_{2}$ & $\mathrm{~V}_{\mathrm{OC}}(\mathrm{mV})$ & $\mathrm{J}_{\mathrm{SC}}\left(\mathrm{mA} / \mathrm{cm}^{2}\right)$ & $\mathrm{FF}$ & $\eta(\%)$ \\
\hline \multicolumn{5}{c}{ Iluminação pela face $\mathrm{n}^{+}$} \\
$\mathrm{Cz}$ & $\mathrm{Sem}$ & $591 \pm 17$ & $31,6 \pm 1,0$ & $0,71 \pm 0,01$ & $13,4 \pm 1,0$ \\
& $\mathrm{Com}$ & $592 \pm 12$ & $31,0 \pm 2,0$ & $0,67 \pm 0,02$ & $12,0 \pm 1,0$ \\
$\mathrm{FZ}$ & $\mathrm{Sem}$ & $601 \pm 1$ & $32,2 \pm 0,1$ & $0,72 \pm 0,01$ & $14,0 \pm 0,1$ \\
& $\mathrm{Com}$ & $604 \pm 1$ & $33,2 \pm 0,2$ & $0,72 \pm 0,01$ & $14,5 \pm 0,1$ \\
\hline \multicolumn{6}{c}{$\mathrm{Cluminação} \mathrm{pela} \mathrm{face} \mathrm{p}^{+}$, com região de BSF de boro e Al } \\
\hline \multirow{6}{*}{$\mathrm{Cz}$} & Sem & $582 \pm 18$ & $20,6 \pm 2,6$ & $0,73 \pm 0,01$ & $8,8 \pm 1,5$ \\
& $\mathrm{Com}$ & $582 \pm 13$ & $22,0 \pm 2,0$ & $0,7 \pm 0,1$ & $8,4 \pm 1,5$ \\
$\mathrm{FZ}$ & Sem & $592 \pm 1$ & $22,2 \pm 0,2$ & $0,73 \pm 0,01$ & $9,7 \pm 0,1$ \\
& Com & $595 \pm 1$ & $23,7 \pm 0,3$ & $0,73 \pm 0,01$ & $10,4 \pm 0,2$ \\
\hline
\end{tabular}


Tabela II - Características elétricas das células solares mais eficientes e valores obtidos mediante simulação com o programa PC-1D.

[Table II - Electrical parameters of the best solar cells and results from simulation by means of the PC1D device-modeling program.]

\begin{tabular}{|c|c|c|c|c|c|c|c|c|}
\hline Subst. & Parâmetros ajustados por simulação & $\mathrm{SiO}_{2}$ & Ilum. & Resultado & $\begin{array}{l}\mathrm{V}_{\mathrm{OC}} \\
(\mathrm{mV}) \\
\end{array}$ & $\begin{array}{c}\mathrm{J}_{\mathrm{SC}} \\
\left(\mathrm{mA} / \mathrm{cm}^{2}\right)\end{array}$ & FF & $\begin{array}{c}\eta \\
(\%) \\
\end{array}$ \\
\hline \multirow{8}{*}{$\mathrm{Cz}$} & $\mathrm{S}_{\mathrm{f}}=4.10^{5} \mathrm{~cm} / \mathrm{s}$ & \multirow{4}{*}{ Com } & \multirow{2}{*}{$\mathrm{n}^{+}$} & Exp.* & 603 & 33,1 & 0,673 & 13,4 \\
\hline & $\mathrm{S}_{\mathrm{p}}=1.10^{5} \mathrm{~cm} / \mathrm{s}$ & & & $\operatorname{Sim} .^{\circ}$ & 603 & 33,2 & 0,669 & 13,4 \\
\hline & $\tau=22 \mu \mathrm{s}$ & & \multirow{2}{*}{$\mathrm{p}^{+}$} & Exp. & 595 & 23,7 & 0,706 & 10,0 \\
\hline & $\mathrm{r}_{\mathrm{S}}^{*}=3,3 \Omega \cdot \mathrm{cm}^{2}$ & & & Sim. & 595 & 23,7 & 0,707 & 10,0 \\
\hline & $\mathrm{S}_{\mathrm{f}}=1.10^{7} \mathrm{~cm} / \mathrm{s}$ & \multirow{4}{*}{ Sem } & \multirow{2}{*}{$\mathrm{n}^{+}$} & Exp. & 602 & 32,3 & 0,719 & 14,0 \\
\hline & $\mathrm{S}_{\mathrm{p}}=1.10^{7} \mathrm{~cm} / \mathrm{s}$ & & & Sim. & 602 & 32,6 & 0,713 & 14,0 \\
\hline & $\tau=55 \mu \mathrm{s}$ & & \multirow[b]{2}{*}{$\mathrm{p}^{+}$} & Exp. & 594 & 22,2 & 0,739 & 9,7 \\
\hline & $\mathrm{r}_{\mathrm{s}}^{*}=2,4 \Omega \cdot \mathrm{cm}^{2}$ & & & Sim. & 592 & 22,3 & 0,750 & 9,8 \\
\hline \multirow{8}{*}{$\mathrm{FZ}$} & $\mathrm{S}_{\mathrm{f}}=1,5 \cdot 10^{5} \mathrm{~cm} / \mathrm{s}$ & \multirow{4}{*}{ Com } & \multirow{2}{*}{$\mathrm{n}^{+}$} & Exp. & 605 & 32,9 & 0,729 & 14,5 \\
\hline & $\mathrm{S}_{\mathrm{p}}=1.10^{5} \mathrm{~cm} / \mathrm{s}$ & & & Sim. & 605 & 33,6 & 0,717 & 14,6 \\
\hline & $\tau=19 \mu \mathrm{s}$ & & \multirow{2}{*}{$\mathrm{p}^{+}$} & Exp. & 596 & 23,6 & 0,740 & 10,4 \\
\hline & $\mathrm{r}_{\mathrm{S}}^{*}=2,2 \Omega \cdot \mathrm{cm}^{2}$ & & & Sim. & 596 & 23,2 & 0,752 & 10,4 \\
\hline & $\mathrm{S}_{\mathrm{f}}=1.10^{7} \mathrm{~cm} / \mathrm{s}$ & \multirow{4}{*}{ Sem } & \multirow{2}{*}{$\mathrm{n}^{+}$} & Exp. & 600 & 32,3 & 0,726 & 14,1 \\
\hline & $\mathrm{S}_{\mathrm{p}}=1.10^{7} \mathrm{~cm} / \mathrm{s}$ & & & Sim. & 600 & 32,6 & 0,740 & 14,0 \\
\hline & $\tau=45 \mu \mathrm{s}$ & & \multirow{2}{*}{$\mathrm{p}^{+}$} & Exp. & 590 & 22,0 & 0,734 & 9,5 \\
\hline & $\mathrm{r}_{\mathrm{s}}{ }^{*}=2,3 \Omega \cdot \mathrm{cm}^{2}$ & & & Sim. & 591 & 22,1 & 0,750 & 9,8 \\
\hline
\end{tabular}

Notas: ${ }^{*}$ - experimental; ${ }^{\circ}$ - simulado.

níveis previstos poderia subir a $\mathrm{J}_{\mathrm{SC}}$ em aproximadamente $1 \mathrm{~mA} / \mathrm{cm}^{2}$ e a eficiência dos dispositivos passivados em até $0,9 \%$ absolutos, mantidas as demais características $\left(\tau\right.$ e $\left.r_{s}{ }^{*}\right)$. Ao ajustar o tempo de vida dos portadores minoritários, tanto para o silício $\mathrm{Cz}$ como para o FZ, verificou-se que o valor ajustado foi menor para células solares que passaram pelo processo de oxidação. Neste caso, embora o óxido de silício passive as superfícies, o processo térmico introduziu contaminantes ou produziu defeitos nas lâminas. Notou-se que as lâminas $\mathrm{FZ}$ apresentaram um $\tau$ menor que o inicial de $165 \pm 12 \mu \mathrm{s}$, mas no caso das lâminas de silício $\mathrm{Cz}$, houve uma melhora neste parâmetro, de 42 para 55 s (antes da oxidação), atribuída ao processo de gettering com fósforo [15]. Quando se compararam as células solares mais eficientes, observou-se que as diferenças entre as fabricadas com silício Cz e FZ são pequenas no que se refere a $\mathrm{V}_{\mathrm{OC}}$ e $\mathrm{J}_{\mathrm{SC}}$. Somente no caso dos dispositivos passivados com $\mathrm{SiO}_{2}$ houve uma diferença na resistência em série e consequentemente no FF. O valor da resistência em série foi elevado para todas as células, mas principalmente para células $\mathrm{Cz}$ com $\mathrm{SiO}_{2}$, com FF abaixo de 0,7 e $\mathrm{r}_{\mathrm{s}}{ }^{*}=3,3 \Omega \cdot \mathrm{cm}^{2}$. Os elevados valores de $\mathrm{r}_{\mathrm{s}}{ }^{*}$ para todas as células solares foram atribuídos à malha posterior de alumínio.

A Tabela III apresenta as características elétricas das células solares mais eficientes e com filme AR sobre a face $\mathrm{p}^{+}$, depositado depois do processo de metalização. Notou-se que para ambos os substratos a eficiência obteve um aumento de aproximadamente $0,7 \%$ absolutos após a deposição do filme AR. O aumento da $\mathrm{J}_{\mathrm{SC}}$ de $2 \mathrm{~mA} / \mathrm{cm}^{2}$ deveu-se ao maior número de fótons absorvidos pela célula fotovoltaica. As células solares mais eficientes processadas com lâminas $\mathrm{Cz}$ não possuíram a camada de $\mathrm{SiO}_{2}$ e atingiram a eficiência de $14 \%$ quando iluminadas pela face $\mathrm{n}^{+}$e de $10,4 \%$ quando iluminadas pela face $\mathrm{p}^{+}$. O dispositivo mais eficiente foi fabricado com silício $\mathrm{FZ}$ e com a passivação de $\mathrm{SiO}_{2}$, alcançando as eficiências de 14,5\% e 11,1\% com iluminação

Tabela III - Características elétricas das células solares mais eficientes, iluminadas pela face $\mathrm{p}^{+}$, com e sem filme antirreflexo de $\mathrm{TiO}_{2}$.

[Table III - Electrical characteristics of the most efficient solar cells, illuminated by $p^{+}$face, with and without $\mathrm{TiO}_{2}$ ARC.]

\begin{tabular}{ccccccc}
\hline Subst. & $\mathrm{SiO}_{2}$ & Filme AR & $\begin{array}{c}\mathrm{V}_{\mathrm{OC}} \\
(\mathrm{mV})\end{array}$ & $\begin{array}{c}\mathrm{J}_{\mathrm{SC}} \\
\left(\mathrm{mA} / \mathrm{cm}^{2}\right)\end{array}$ & FF & $\begin{array}{c}\eta \\
(\%)\end{array}$ \\
\hline \multirow{4}{*}{$\mathrm{Cz}$} & \multirow{2}{*}{$\mathrm{Com}$} & $\mathrm{Sem}$ & 595 & 23,7 & 0,706 & 10,0 \\
& & $\mathrm{Com}$ & 593 & 25,7 & 0,702 & 10,7 \\
& \multirow{2}{*}{$\mathrm{Sem}$} & $\mathrm{Sem}$ & 594 & 22,2 & 0,739 & 9,7 \\
& $\mathrm{Com}$ & 592 & 24,2 & 0,728 & 10,4 \\
\hline \multirow{4}{*}{$\mathrm{FZ}$} & \multirow{2}{*}{$\mathrm{Com}$} & Sem & 596 & 23,6 & 0,740 & 10,4 \\
& \multirow{2}{*}{ Sem } & Com & 594 & 25,4 & 0,735 & 11,1 \\
& & Sem & 590 & 22,0 & 0,734 & 9,5 \\
& & Com & 590 & 24,1 & 0,726 & 10,3 \\
\hline
\end{tabular}


a)

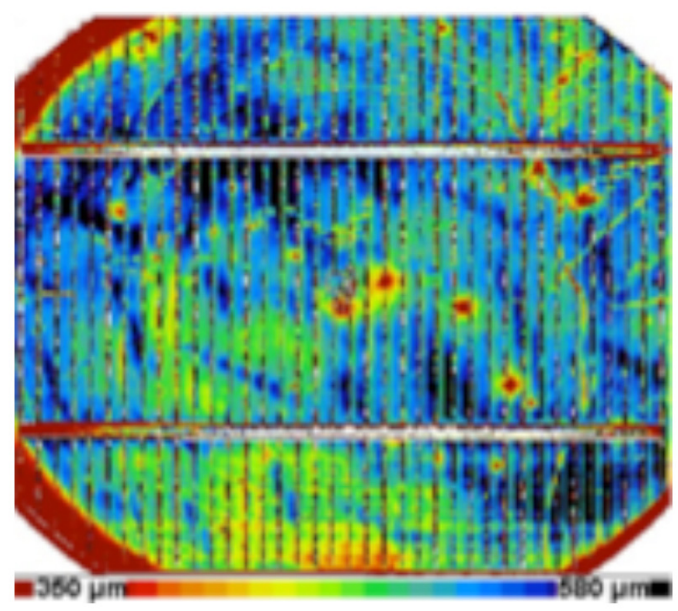

c)

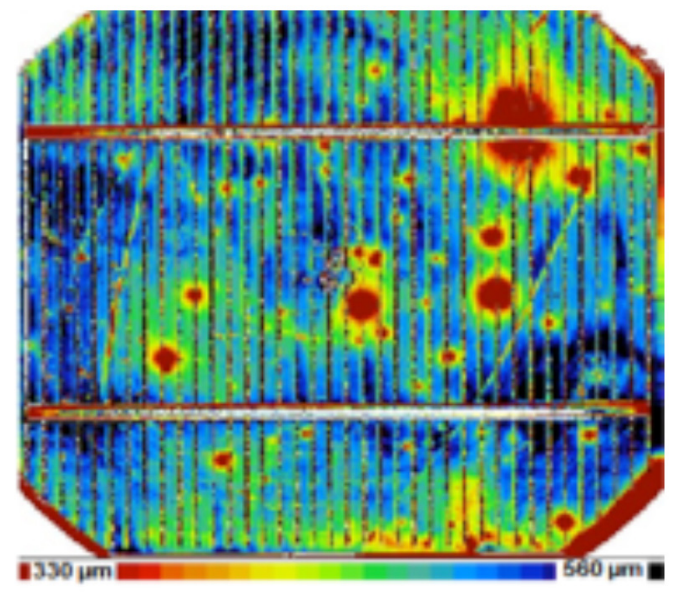

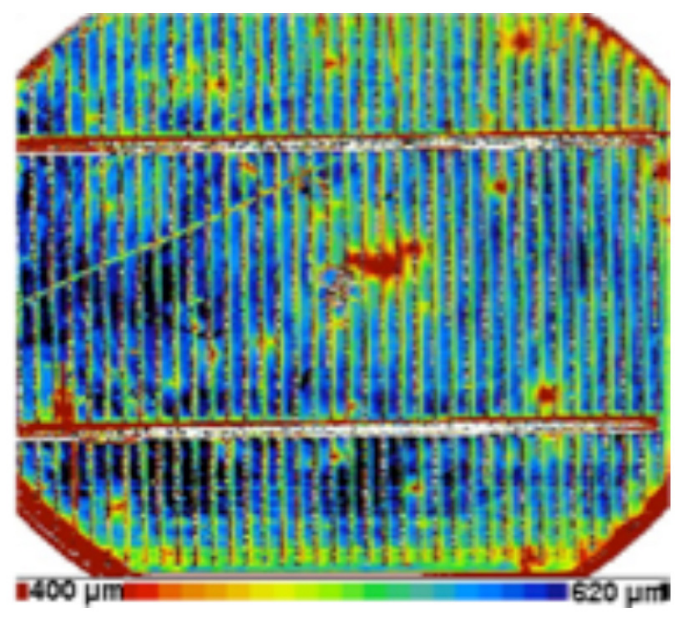

b)

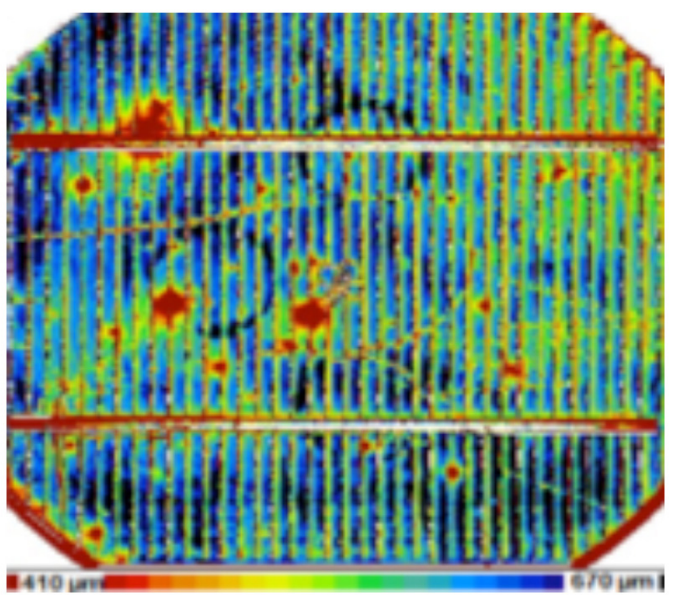

Figura 3: Mapas do comprimento de difusão dos portadores minoritários das melhores células solares em Si-Cz: (a) sem óxido, com $\mathrm{L}_{\mathrm{Dmédio}}=$ $507 \mu \mathrm{m}$; e (b) com óxido e $\mathrm{L}_{\text {Dmédio }}=556 \mu \mathrm{m}$; e fabricadas com Si-FZ: (c) sem óxido, com $\mathrm{L}_{\text {Dmédio }}=490 \mu \mathrm{m}$; e (d) com $\mathrm{SiO}_{2}$ e $\mathrm{L}_{\text {Dmédio }}=582 \mu \mathrm{m}$. [Figure 3: Two-dimensional distribution of the minority carrier diffusion length of the best Cz-Si solar cells: (a) without oxide, with $L_{\text {Daverage }}=507 \mu \mathrm{m}$; and $(b)$ with oxide and $L_{\text {Daverage }}=556 \mu \mathrm{m}$; and of the best FZ-Si solar cells: $(c)$ without oxide, with $L_{\text {Daverage }}=490 \mu \mathrm{m} ;$ and (d) with oxide and $L_{\text {Daverage }}=582 \mu \mathrm{m}$.]

pela face $\mathrm{n}^{+} \mathrm{e} \mathrm{p}^{+}$, respectivamente. Estes resultados foram semelhantes aos obtidos em [11], no entanto neste trabalho o processo de fabricação tem um menor número de passos, as células solares bifaciais são de maior área e considerou-se a barra coletora na área ativa do dispositivo. Considerando os valores de velocidade de recombinação em superfície anteriormente citados e previstos em [17, 18], um $\tau$ de $55 \mu$ s no final do processamento e a $\mathrm{r}_{\mathrm{s}}{ }^{*}$ reduzida para $1,0 \Omega . \mathrm{cm}^{2}$ (valor que pode ser obtido em células solares com malha metálica otimizada), a eficiência na face $\mathrm{n}^{+}$obtida mediante simulação com o programa PC-1D seria de $16,2 \%$ e a da face $\mathrm{p}^{+}$seria de $13,3 \%$, sendo estes os limites práticos para a estrutura estudada neste trabalho.

A Fig. 3 apresenta a distribuição do comprimento de difusão dos portadores de carga minoritários obtida pela técnica LBIC para os dispositivos mais eficientes em lâminas $\mathrm{Cz}$ e FZ, com e sem óxido. Embora o tempo de vida inicial dos portadores de carga minoritários nas lâminas FZ seja quatro vezes o valor das lâminas $\mathrm{Cz}$ no início do processamento, o que indicaria que da mesma forma o $\mathrm{L}_{\mathrm{D}}$ deveria ser quatro vezes maior, os valores médios do comprimento de difusão $\left(\mathrm{L}_{\text {Dmédio }}\right)$ foram relativamente muito próximos. Para células $\mathrm{Cz}$, sem $\mathrm{SiO}_{2}, \mathrm{~L}_{\text {Dmédio }}=507 \mu \mathrm{m}$ e com $\mathrm{SiO}_{2}, \mathrm{~L}_{\text {Dmédio }}=556 \mu \mathrm{m}$. Em dispositivos com silício $\mathrm{FZ}$, sem $\mathrm{SiO}_{2}, \mathrm{~L}_{\text {Dmédio }}=490 \mu \mathrm{m}$ e com $\mathrm{SiO}_{2}, \mathrm{~L}_{\text {Dmédio }}=582 \mu \mathrm{m}$.

\section{CONCLUSÕES}

Foram fabricadas e caracterizadas células solares bifaciais em substratos finos com o objetivo de analisar a passivação de superfícies com $\mathrm{SiO}_{2}$ crescido termicamente e avaliar a influência do tipo de lâmina utilizado no processamento. Constatou-se que o óxido de silício reduziu a recombinação nas superfícies tipo $\mathrm{n}$ e tipo $\mathrm{p}$ dos dispositivos processados com lâminas de silício FZ (float zone) e Cz (Czochralski), mas os valores da velocidade de recombinação em superfície foram uma ordem de magnitude acima dos valores publicados por outros autores. Em relação ao tipo de substrato, embora as lâminas de silício FZ tivessem maior tempo de vida dos portadores de carga minoritários no início do processamento que as lâminas $\mathrm{Cz}$, a tensão de circuito aberto e a densidade de corrente de curto-circuito 
dos dispositivos fabricados foram similares. Isto ocorreu porque o processo introduziu limitações para as lâminas FZ. No caso das lâminas que não passaram por oxidação, o processamento incrementou o tempo de vida dos portadores minoritários nas lâminas $\mathrm{Cz}$. A célula solar bifacial fina mais eficiente foi fabricada com silício FZ e superfícies oxidadas, atingindo eficiência de $14,5 \%$ e $11,1 \%$, para iluminação pela face $\mathrm{n}^{+}$e $\mathrm{p}^{+}$, respectivamente. A melhor célula solar com $\mathrm{Si}-\mathrm{Cz}$ não foi processada com a camada de $\mathrm{SiO}_{2}$ e atingiu a eficiência de $14 \%$ quando iluminada pela face $\mathrm{n}^{+}$e de $10,4 \%$ quando iluminada pela face $\mathrm{p}^{+}$. Da comparação dos resultados das células solares bifaciais finas fabricadas com silício $\mathrm{Cz}$ e $\mathrm{FZ}$ pôde-se concluir que não houve vantagem em usar substratos de maior tempo de vida dos portadores de carga minoritários inicial com o processo desenvolvido. No que se refere à camada de $\mathrm{SiO}_{2}$, observou-se que ocorreu passivação das superfícies tanto em dispositivos com silício FZ como Cz. Porém, os resultados para o silício $\mathrm{Cz}$ foram pouco significativos e faz-se necessária a otimização do processo térmico de crescimento da camada de óxido de silício.

\section{AGRADECIMENTOS}

O trabalho foi realizado no âmbito do projeto "Células solares bifaciais em substratos finos e com região $\mathrm{p}^{+}$ localizada", Contrato PUCRS-CEEE 9942397. Os autores agradecem também o apoio do CNPq e FINEP, por meio do projeto "Desenvolvimento de células solares eficientes em lâminas de silício tipo n" e à equipe do NT-Solar/PUCRS pelo apoio na fabricação das células solares.

\section{REFERÊNCIAS}

[1] A. Goodrich, P. Hacke, Q. Wang, S.B.R. Margolis, T. James, M. Woodhouse, Sol. Energy Mater. Sol. Cells 114 (2013) 110.

[2] L. Janßen, M. Rinio, D. Borchert, H. Windgassen, D. Bätzner, H. Kurz, Prog. Photovolt. Res. Appl. 15 (2007) 469. [3] A. Cuevas, in Proc. 20 ${ }^{\text {th }}$ Eur. Photovolt. Solar Energy Conf. Exhib., WIP, Barcelona, Espanha (2005) 801.

[4] I. Zanesco, E. Lorenzo, Prog. Photovolt. Res. Appl. 10 (2002) 361.

[5] A. Moehlecke, F.S. Febras, I. Zanesco, Solar Energy 96 (2013) 253.

[6] R. Guerro-Lemus, R. Vega, T. Kim, A. Kimm, L.E Shephard, Renew. Sust. Energ. Rev. 60 (2016) 1533.

[7] F. Fertig, S. Nold, N. Wohrle, J. Greulich, I. Hädrich, K.
Krau $\beta$, M. Mittag, D. Biro, S. Rein, R. Preu, Prog. Photovolt. Res. Appl. 24 (2016) 800.

[8] H. Ohtsuka, M. Sakamoto, K. Tsutsui, Y. Yazawa, Prog. Photovolt. Res. Appl. 8, 4 (2000) 385.

[9] L. Yang, Q.H. Ye, A. Ebong, W.T. Song, G.J. Zhang, J.X. Wang, Y. Ma, Prog. Photovolt. Res. Appl. 19 (2011) 275.

[10] L. Janßen, H. Windgassen, D.L. Bätzner, B. Bitnar, H. Neuhaus, Sol. Energy Mater. Sol. Cells 93 (2009) 1435.

[11] F. Recart, "Evaluación de la serigrafia com técnica de metalización para células solares eficientes", Tese Dr., Un. País Vasco, Bilbao, Espanha (2001).

[12] L. Pérez, J. Coello, I. Freire, K. Varner, R. Lago, G. Bueno, C. Cañizo, A. Luque, in Proc. 20 ${ }^{\text {th }}$ Eur. Photovolt. Solar Energy Conf. Exhib., WIP, Barcelona, Espanha (2005) 891.

[13] S. Steckemetz, A. Metz, R. Hezel, in Proc. 17 ${ }^{\text {th }}$ Eur. Photovolt. Solar Energy Conf. Exhib., WIP, Munique, Alemanha (2001) 1902.

[14] A. Moehlecke, V.C. Osório, I. Zanesco, Mater. Res. 17, 5 (2014) 1328.

[15] V.C. Osório, A. Moehlecke, I. Zanesco, Mater. Res. Express 3 (2016) 1.

[16] J.C. Jimeno, G. Bueno, R. Lago, I. Freire, L. Pérez, F. Recart, I. Hoces, N. Azkona, J. Alonso, P. Sánchez-Friera, S.W. Glunz, G. Emanuel, R. Ruiz, A. Pohl, W. Wolke, M. Schubert, I. Gavilanes, M. Ezker, E. Zugasti, A. Turumbay, H. Sato, J. Bragagnolo, P.M. Nasch, S. Ostapenko, A. Belyaev, W. Dallas, O. Polupan, K. Albertsen, A. Shaikh, H. Kerp, J. Salami, in Proc. 22 $2^{\text {nd }}$ Eur. Photovolt. Solar Energy Conf. Exhib., WIP, Milão, Itália (2007) 875.

[17] V.C. Osório, A. Moehlecke, I. Zanesco, Rev. Bras. Energia Solar III, 2 (2012) 86.

[18] I. Zanesco, A. Moehlecke, J.L. Pinto, M. Ly, in Conf. Record $38^{\text {th }}$ Photovolt. Special. Conf., IEEE, Austin, EUA (2012) 2284.

[19] WT-2000PV, “User manual: measurement tool for solar cell manufacturing", http://www.semilab.com, acesso 4 abril 2017.

[20] P.A. Basore, D.A. Clugston, in Conf. Record $26^{\text {th }}$ Photovolt. Spec. Conf., IEEE, Anaheim, EUA (1995) 207.

[21] A. Cuevas, G. Giroult-Matlakowski, P.A. Basore, C. Dubois, R.R. King, in Conf. Record First World Conf. Photovolt. Energy Convers., IEEE, Hawai, EUA (1994) 1446.

[22] A. Das, "Development of high-efficiency boron diffused silicon solar cells", PhD dissert., Georgia Inst. Techn., Atlanta, EUA (2012).

(Rec. 24/04/2017, Rev. 06/07/2017, Ac. 22/08/2017) 